\title{
A Great Achievement of Calculated and Experimental Results of Char Kinetic Rate in Woody Mahogany Pyrolysis
}

\author{
Widya Wijayanti*, Mega Nur Sasongko \\ Department of Mechanical Engineering, Brawijaya University, 65145, Indonesia
}

\begin{abstract}
In the pyrolysis process, it is needed to know the value of $k$ (rate costant) to know the rate of reaction that occurs. It is needed to calculate $\mathrm{k}$ caused by $T$ effect due to the reason that it is extremely difficult experimentally to find rate constants. The pyrolysis process was carried out for three hours with the minimum condition of Oxygen using mahogany wood. It was used the pyrolysis temperature variations of $250^{\circ} \mathrm{C}$ to $800^{\circ} \mathrm{C}$. The results showed the increasing temperature and decreasing mass of char as long as the process to obtain, the kinetic rate of char $k$. We used two calculation approaches method to find the calc ulated $k$. Fristly, it used the total kinetic rate model equation with the equation $k_{T}=60.3 e^{-}$ 2028.4/T and the second one, it was used the local kinetic rate model. In the local kinetic rate approached, it was divided the 3 temperature ranges; $k_{I}$ in the range of $28^{\circ} \mathrm{C}-250^{\circ} \mathrm{C}$ was $k_{1}=539.1 e^{-2907.3 / T}, k_{2}$ in the range of $250^{\circ} \mathrm{C}$ to $500^{\circ} \mathrm{C}$ was $k_{2}=27.11 e^{-1424 / T}$; and $k_{3}$ in the range of at range $500^{\circ} \mathrm{C}$ to $800^{\circ} \mathrm{C}$ was $k_{3}=572.4 e^{-4549.2 / T}$. Then, by using the found $k$ values, it was found the great achievement results that the decreasing mass of char in the calculation was coincide with the experimental results. It was used both kinetic rate methods depending on the required energy was needed in the pyrolysis process; at low pyrolysis temperatures, the appropriate kinetic rate model was a local kinetic rate model, and for pyrolysis at high temperatures of $600^{\circ} \mathrm{C}$ to $800^{\circ} \mathrm{C}$, the accurate kinetic rate model was the total kinetic rate model.
\end{abstract}

\section{Introduction}

Due the pyrolysis is a chemical reaction, the rate of the reaction depends on the reaction mechanism. It simply breaks apart, in which woody biomass produce char+tar+gas, eventhough in the study; it was only focus on the char production measurement. It was required large enough energy and it takes a lot longer than combustion. One of the crucial parameters to generate the energy is heating to break down the biomass components such as cellulose, hemicellulose and lignin. It needs the differ temperatures to decompose its components to be their products [1]. If the pyrolysis process is conducted in the different temperatures, it will affect not only in the products, but also it will influence in its reaction rate.

If the previous study [2] had examined the kinetic studies of pinewood pyrolysis by using thermogravimetric analysis (TGA), in the study; we use pyrolysis pilot plant by measuring the

"Corresponding author: widya dinata@ub.ac.id 
change of biomass mass during the process. We used the real pilot plant because the actual reaction scheme of wood pyrolysis is extremely complex because of the formation of over a hundred intermediate products. The pyrolysis of wood is, therefore, generally modeled on the basis of apparent kinetics [2]. Furthermore, it is needed easier method to predict the pyrolysis mechanism. It will be understood how optimal the appropriate pyrolysis temperature. Accordingly, there is no excess energy to produce char. It is implementated to find out a detail process occuring in the pyrolysis, such as the biomass changes into the products in a certain time. The study aims at generating kinetic data for biomass pyrolysis and exploring its simplicity to kinetic models and make meaningful kinetic predictions.

Modeling the kinetic rate, it can be estimated the reduction of biomass to be char occurring in elapsed time of pyrolysis. Afterwards, the kinetic rate will be modeled and be validated by using experimental data. Then, the appropriate model and the kinetic rate equations will be found. Numerous works on kinetic studies of wood have been reported in literature [2-5]. Pyrolysis will produce some complex decompositions, so it is necessary to understand how large the kinetic rate is to predict the mass reduction that occurs and how large the energy is needed to break down the biomass elements.

During the pyrolysis process, the change of biomass into char in elapsed time is determined by :

$$
\frac{d m}{d t}=-k f(x)
$$

where $\frac{\mathrm{dm}}{\mathrm{dt}}$ is the mass change in elapsed time $(\mathrm{g} / \mathrm{min}), k$ is rate constant $\left(\mathrm{min}^{-1}\right), k$ for the experimental results is defined by $k$ actual while $k$ obtained by calculation is defined as $k$ total $/ k$ local.

Then, it was confirmed by experimental data of the change of mass

$$
\frac{d m}{d t}=-k \frac{m-m \sim}{m o-m \sim}
$$

consisted of the initial mass $\left(m_{o}\right)$, the final mass $\left(m_{\sim}\right)$, and the calculated mass $(m)$, as well as the rate constant $(k)$. Because the rate constant is influenced by the pyrolysis temperature, $\mathrm{k}$ will be replaced by the equation that similar Arhennius equation. It will be obtained some $k$ and found the kinetic rate char mathematical model. It will use the local kinetic rate and the total kinetic rate. The local kinetic rate have the rate constant ( $k$ local) obtained from the plotting of each temperature range, at a temperature range of $250^{\circ} \mathrm{C}$ to $800^{\circ} \mathrm{C}$. Here, we found the three constant rates. Meanwhile, the total kinetic rate is the constant rate ( $k$ total) gained from the plotting of the $k$ values of all points from a temperature of $28^{\circ} \mathrm{C}$ to $800^{\circ} \mathrm{C}$.

Then, the mathematical model of kinetic rate char will be validated with experimental data. This validation is used to know the truth of the agreement of $k$, so that it can be used as a suggestion for optimizing parameters in pyrolysis.

\section{Methodology}

The experimental device was used a vertical pyrolizer [6-9], however we used a container hang up the weight balance [4] to measure the change of solid yield (char) along the pyrolysis process.

The pyrolysis temperature were varied at $250^{\circ} \mathrm{C}, 350^{\circ} \mathrm{C}, 450^{\circ} \mathrm{C}, 500^{\circ} \mathrm{C}, 600^{\circ} \mathrm{C}, 700^{\circ} \mathrm{C}$ and $800^{\circ} \mathrm{C}$. It was started from the ambient temperature. The raw material used was mahogany needle particles with 80 gram mass and $20 \mu \mathrm{m}$ size. Before putting in the pyrolyzer, the sample was dried using an oven for 1-2 hours so that the water content wood around $2 \%$. Afterwards, the sample was put into the beaker then inserted into the pyrolyzer. Before starting the pyrolisis process, Nitrogen was flowed into pyrolizer to suppress Oxygen until the Oxygen content around $2 \%$ furnace volume. Next, the thermocontroller was installed at the pyrolysis temperature. The pyrolysis process was conducted during 3 hours at every the pyrolysis temperature. Every 3 minutes, it would be recorded the change of biomass mass or the formed char. After the pyrolysis process was accomplished, the char was weighed and the final volume was measured. 


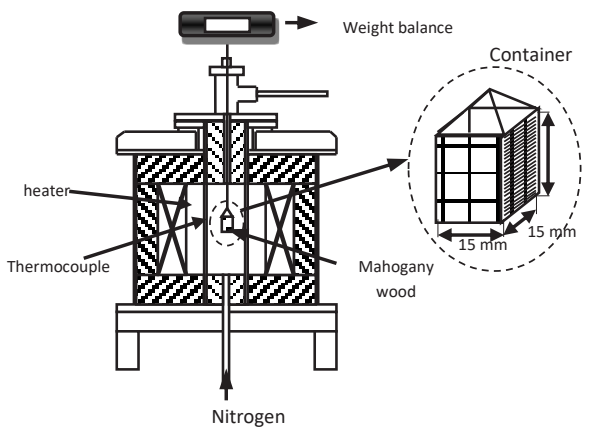

Fig. 1. Pyrolysis experimental run to measure the mass change of biomass

\section{Results and Disscussion}

Fig. 2 shows the elapsed time against the temperature change with some variations in the setting pyrolysis temperature and the relationship of pyrolysis temperature with char mass changes.. The setting pyrolysis temperature variations are $250^{\circ} \mathrm{C}, 350^{\circ} \mathrm{C}, 450^{\circ} \mathrm{C}, 500^{\circ} \mathrm{C}$, $600^{\circ} \mathrm{C}, 700^{\circ} \mathrm{C}, 800^{\circ} \mathrm{C}$ in which to reach the temperature each experiment takes durimg 3 hours. Then, the graph can be used to determine the actual kinetic rate of each pyrolysis time. Comprehensively, the figure presents that the greater the pyrolysis temperature, the greater the reduction of the biomass mass to be char [9]. It indicates a very rapid pyrolysis reaction because the higher the temperature, the the higher the kinetic energy to decay the mahogany wood components resulting the huge decomposition of biomass components.
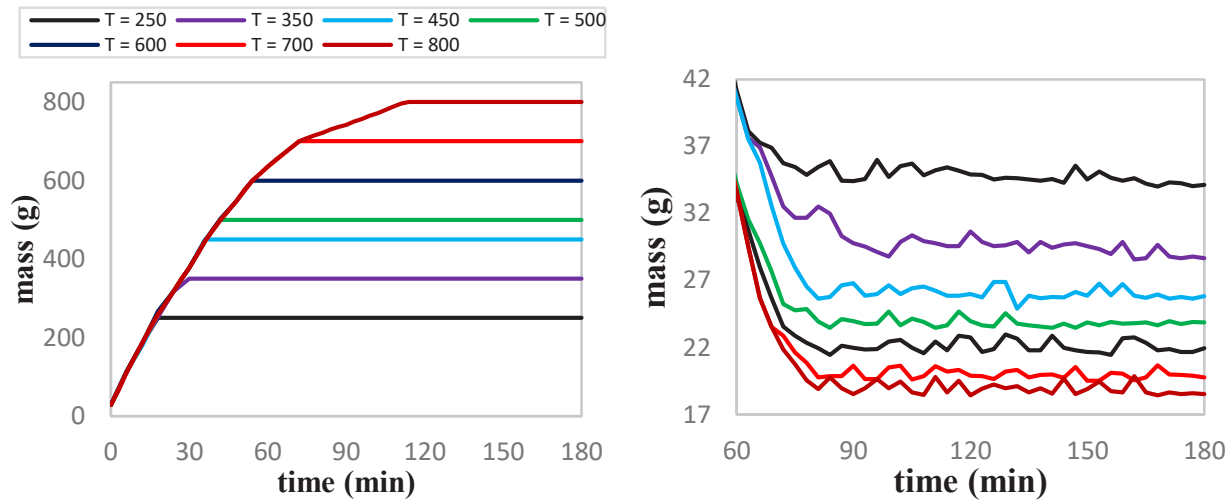

Fig. 2. Increasing temperature and decreasing mass of biomass to be char in elapsed time

The main components of mahogany wood consist of $40 \%-45 \%$ cellulose, $24 \%-40 \%$ hemicellulose, and 18\%-25\% lignin. These components will decompose at the different temperatures. According to the previous research [10], the hemicellulose will decompose at the pyrolysis temperature of $200^{\circ} \mathrm{C}-260^{\circ} \mathrm{C}$, whereas the hemicellulose will decay at $260^{\circ} \mathrm{C}$ to $350^{\circ} \mathrm{C}$, and lignin will decompose at $350^{\circ} \mathrm{C}$ to $800^{\circ} \mathrm{C}$, so it will be divided as some range of temperature as follows:

I. At $250^{\circ} \mathrm{C}$, evaporation occurs in the biomass and a little part of the hemicellulose causing a reduction of the biomass mass. It appears that the biomass reduction at $250^{\circ} \mathrm{C}$ is the least biomass reduction if it is compared to other pyrolysis temperatures because the biomass components except water have not been decomposed yet. 
II. In addition to the water evaporation, the hemicellulose is completely decomposed and most of the cellulose will decompose completely at $350^{\circ} \mathrm{C}$. As a result, at this temperature, the mass loss will be greater than the lost mass at $250^{\circ} \mathrm{C}$.

III. Although there is still a few water evaporation, at temperatures $450^{\circ} \mathrm{C}$ to $800^{\circ} \mathrm{C}$, all biomass components including lignin undergo extreme decomposition. As a result, char formation due to the reduction of biomass occurs with increasing the pyrolysis temperature. The higher the pyrolysis temperature, the lignin undergoes increasingly significant decomposition. Therefore, the highest biomass reduction (char formation) occurs at the highest temperature of $800^{\circ} \mathrm{C}$ which is the highest temperature of pyrolysis.
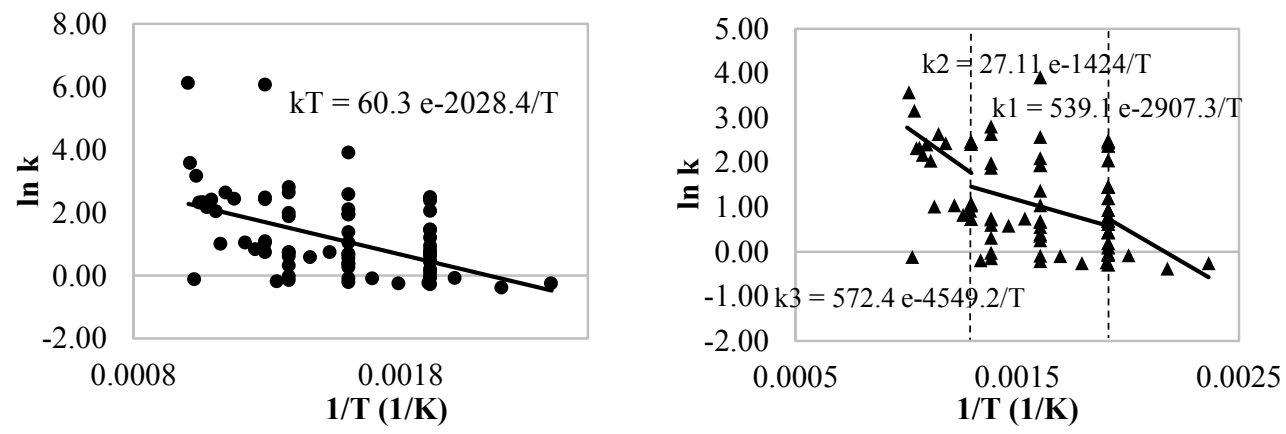

Fig. 3. Total and local kinetic rate in Arrhenius plot

Furthermore, from the obtained experimental results (Fig. 3), the pyrolysis kinetic rate equation can be known. The calculation of the kinetic rate in pyrolysis process in this study use two methods such as by using total kinetic rate and by using local kinetic rate. The total kinetic rate is the kinetic rate obtained from plotting the $k$ value obtained from the experimental results during pyrolysis process from temperature $28^{\circ} \mathrm{C}$ to $800^{\circ} \mathrm{C}$. For the total kinetic rate, the obtained equation is $k_{T}=60.3 e^{-2082.4 / T}$.

Meanwhile, the local kinetic rate is the kinetic rate that the temperature range during pyrolysis process is divided into 3 ranges based on the decomposition temperature of each of its biomass components, as described in Fig. 3 and in the previous study [4]. In range 1, ie at temperature $28^{\circ} \mathrm{C}$ to $250^{\circ} \mathrm{C}$ in which only evaporation process occurs. Then at temperature $250^{\circ} \mathrm{C}$ to $500^{\circ} \mathrm{C}$, it takes place evaporation process + cellulose + hemicellulose decomposition. In the last range, it occurs the decompotition process both of evaporation process and all biomass components. Finally, from these three ranges, it is got the 3 equations of $k$ from each temperature ranges. Range I obtained the equation $k_{1}=539.1 e^{-}$ ${ }^{2907.3 / T}$. At temperature range II $250^{\circ} \mathrm{C}$ to $500^{\circ} \mathrm{C}$, it is obtained the equation $k_{2}=27.11 e^{-}$ ${ }^{1424 / T}$. In the range III $500^{\circ} \mathrm{C}$ to $800^{\circ} \mathrm{C}$, it is found the equation $k_{3}=572.4 e^{-4549.2 / T}$. Afterwards, $k$ will be used to calculate the mass of char during the pyrolysis process as determined by equation 2 .

Before calculating the mass of char occurring at the pyrolysis process, firstly, we will look at the differences in $k$ values of the two previously mentioned methods. In general, the higher the pyrolysis temperature, the value of $k$ (rate constant) will also be greater. This applies at the equations both using the total and local kinetic rate. It is because the higher the temperature, the greater the kinetic energy to break up the biomass. Consequently, the biomass can decompose quickly. This is in accordance that expressed at the previous research $[1,6,8,9]$. From the calculation $k, k$ with using the model of total kinetic rate has a very large range of $k$ values and the value of $k$ gradient is near constant, ie around 1.3 minutes $^{-1}$. Meanwhile, the $k$ value for the local kinetic rate model has fluctuated values. That is, in the local kinetic rate model, the amount of energy to break the biomass varies in 
which it depends on the temperature of its biomass decomposition. In contrast, in the total kinetic rate model it is required the same amount of energy to break the biomass component. It means whatever the conditions; the energy used to break the biomass component is the same energy.

From the $k$ value obtained, then the $k$ will be used to predict the mass char formed during the pyrolysis process at each pyrolysis temperature setting. Then to find out how accurate the value of $k$, it will be compared the calculated results of the mass char both using the $k$ local and $k$ total) to the experimental results in laboratory. Then, the agreements of the calculated results and the experimental results will be shown in Fig. 4 and Fig. 5.
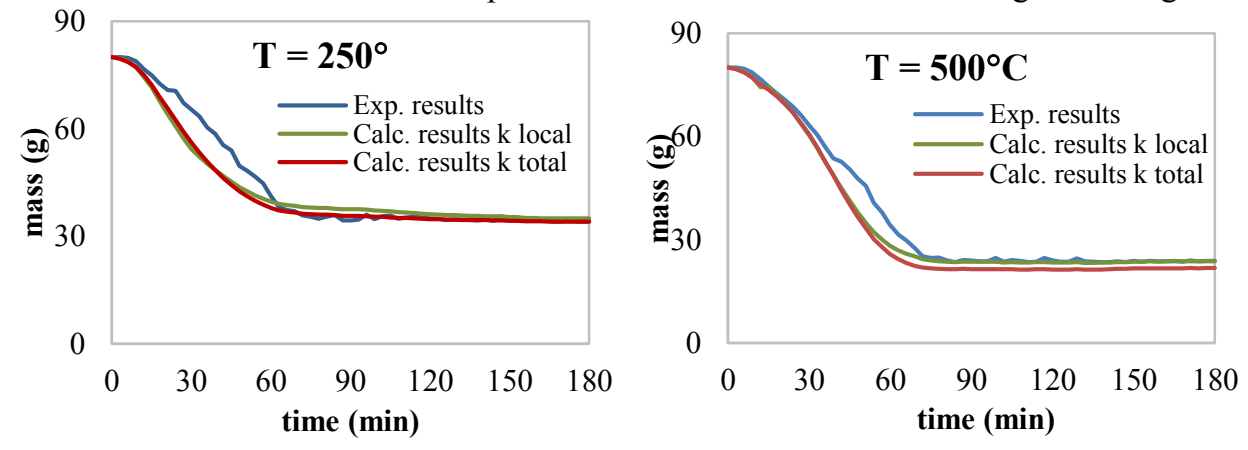

Fig. 4. The decreasing of char at $\mathrm{T}=250^{\circ} \mathrm{C}$ to $\mathrm{T}=500^{\circ} \mathrm{C}$
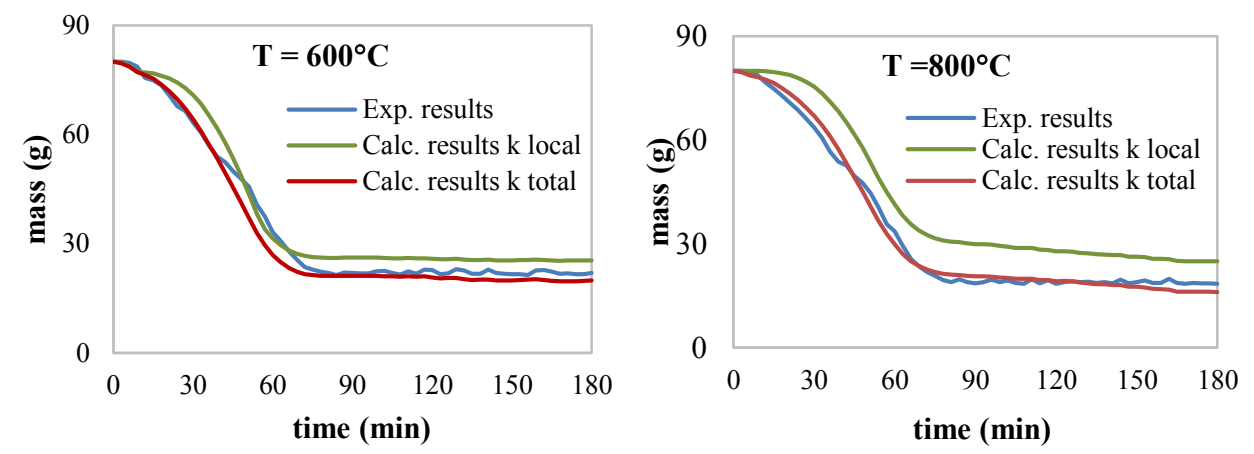

Fig. 5. The decreasing of char at $\mathrm{T}=600^{\circ} \mathrm{C}$ to $\mathrm{T}=800^{\circ} \mathrm{C}$

From Fig. 4, it can be seen that at temperatures $250^{\circ} \mathrm{C}$ to $500^{\circ} \mathrm{C}$, the calculated results that almost agree with the experimental results are the calculated results using the local $k$ model, eventhough around 20-80 minutes pirolysis time, the experimental results have values above the calculated results. It is due to the large evaporation process occurs, so it will affect the mass of measured biomass. As a result, the mass of char in the experimental results tends to be larger. The local $k$ model is more appropriate than the total $\mathrm{k}$ model, because it is needed a greater energy in the initial pyrolysis process. Therefore, the initial acceleration energy of pyrolysis process is greater than when pyrolysis is already running even for high temperatures. The initial acceleration of energy for pyrolysis is greater than the energy required when pyrolysis is already running even for pyrolysis at the higher temperatures. In addition, when the pyrolysis is at a low temperature, the reaction pyrolysis process is endothermic, in which the biomass only requires heat to break down its biomass compounds [1]. 
In opposite, at temperature $600^{\circ} \mathrm{C}$ to $800^{\circ} \mathrm{C}$, the calculated results of the total kinetic rate model agree with the experimental results. In Fig. 5, the calculated results of the local kinetic rate model are above the experimental results significantly. It is because the values of $k$ local on the calculation results are smaller than the actual values in the experiment results, so the calculated results (mass reductions) during the pyrolysis process becomes smaller if it uses the local kinetic rate equation model. Afterwards, if it is connected to Fig. 5 and Fig. 6, the rate constant $k$ of the local kinetic rate is greater than the total kinetic rate. It means that the pyrolysis process conducted at above $\mathrm{T}=600^{\circ} \mathrm{C}$ required the same amount of energy to break the biomass component. It means whatever the conditions; the energy used to break the biomass component is the same energy. It is because when the pyrolysis is running, the required energy goes constant. Although theoretically, a great energy is required to decompose the biomass, but the exothermic reaction to the pyrolysis process due to biomass decompositions will give the great energy in pyrolysis at high temperature temperature [1].

\section{Summary}

The research on predicting the kinetic rate of the pyrolysis reaction has been done. It was presented by determination of mathematical models resulting the kinetic reaction rate constants using two models. The first model used the total kinetic rate model and another applied the local kinetic rate model. From both models, it can be concluded that the validation between the calculated results and the experimental results accomplished with a great achievement. It was obtained that the agreements were very precisely, but with different conditions approach;

1. At low pyrolysis temperatures ranging from $250^{\circ} \mathrm{C}$ to $500^{\circ} \mathrm{C}$, the appropriate kinetic rate model was a local kinetic rate model since the greatest energy was needed at the beginning of pyrolysis.

2. For pyrolysis at high temperatures of $600^{\circ} \mathrm{C}$ to $800^{\circ} \mathrm{C}$, the accurate kinetic rate model was the total kinetic rate model. It was because when pyrolysis was running, the required energy remained constant and coupled with the energy produced by the exothermic reaction due to the biomass decomposition taking place at high temperatures.

\section{References}

1. Tanoue, K.-I., Wijayanti, W., Yamasaki, K., Taniguchi, M., Sasauchi, K.-I., Nihon Energi Gakkaishi/Journal of the Japan Institute of Energy 89, 10 (2010)

2. Di Blasi, Progress in Energy and Combustion Science, 34, 1 (2008)

3. C.A. Koufopanos, N. papayannakos, G. Maschio, A. Lucchesi, The Canadian J. of Chemical Eng., 69, 4 (1991)

4. Wijayanti, W., Tanoue, K.-I., Suetomi, T., Taniguchi, M., Sasauchi, K.-I., AIChE Annual Meeting, 11 (2011)

5. Wijayanti, W., Sasongko, M.N., AIP Conference Proceedings 1717, (2016)

6. Wijayanti, W., Sasongko, M.N., Purnami, ARPN J. of Eng. and App. Sciences 11, 22016)

7. Wijayanti, W., Applied Mechanics and Materials 493, 179-185, (2014)

8. Wijayanti, W., Applied Mechanics and Materials, 664, 215-220, (2014)

9. Wijayanti, W., Tanoue, K.-I., Energy Procedia 32, 145-152, (2013)

10. D Mohan, CU Pittman, PH Steele, Pyrolysis of wood/biomass for bio-oil: a critical review. Energy \& fuels (2006) 